\title{
What Role Do Language Learning Mindsets Play in English Medium Instruction? A Comparison of Engineering and Business Administration in Turkey
}

Dogan Yuksel, Department of Foreign Language Education, Kocaeli University

(iD https://orcid.org/0000-0002-3860-7719

doganyuksel@gmail.com

Samantha Curle, Department of Education, University of Bath

https://orcid.org/0000-0003-3790-8656

samanthamcurle@gmail.com

Sibel Kaya, Department of Primary Education, Kocaeli University

https://orcid.org/0000-0001-8417-3627

sibel.kaya@kocaeli.edu.tr

\begin{abstract}
This article explores the relationship between Turkish undergraduate students' language learning mindsets, English language achievement, and English medium instruction (EMI) academic success. Student test score data on an EMI course and an English language course were collected from fourth year students studying mechatronics engineering $(n=68)$ and business administration $(n=75)$ at a public university. Students also responded to the Language Learning Mindsets Inventory (Lou \& Noels, 2019). Regression analyses revealed that both incremental (positively) and entity (negatively) mindsets predicted academic success in engineering. Neither mindset was a statistically significant predictor of mechatronics engineering students' English language achievement. Business administration students' academic success and English language achievement were both statistically significantly predicted by both incremental (positively) and entity (negatively) mindsets. These results are discussed according to discipline-based differences in EMI courses and pedagogical implications are explored.
\end{abstract}

Keywords: Turkey, language learning mindsets, English medium of instruction (EMI), success, English language achievement, higher education 


\section{INTRODUCTION}

Language learning mindsets (LLMs) are beliefs in a specific domain about whether language learning ability is made up of fundamental, pre-determined traits (i.e., fixed mindset, entity theory) or malleable dispositions that can be cultivated (i.e., growth mindset, incremental theory; Lou \& Noels, 2019). According to Ryan and Mercer (2012), entity theory assumes a fixed mindset which views success as a "function of pre-existing natural talent" (p. 6), whereas incremental theory includes a growth mindset, which "values effort over talent" (p. 6). This paper adopts this definition of language learning mindsets. Whether or not language learning mindsets play a role in higher education (HE) teaching and learning contexts where English is the Medium of Instruction has yet to be explored in the research literature (Curle et al., 2020a). This article presents a study that is an initial step in filling this research gap.

It is argued that mindsets determine how individual learners approach learning (Lou \& Noels, 2019). This is important because it is believed that how a learner approaches learning regulates the setting of goals, the use of strategies, and the deployment of effort in a specific field (Ryan \& Mercer, 2012). These in turn might then have a direct impact on a students' academic success (Dweck \& Leggett, 1988). Empirical research has shown that a growth mindset tends to contribute to academic success both directly (see Muller \& Dweck, 1998) and indirectly (see Blackwell et al., 2007). However, some studies claim that mindsets do not have any predictive power in terms of students' academic achievement (Bahník \& Vranka, 2017). These contradictory findings illustrate a need for further research into the relationship between mindsets and academic achievement. This study addresses this research gap. Furthermore, no prior study (see Macaro et al., 2018) has explored the relationship between language learning mindsets, academic achievement, as well as language achievement in a HE context adopting English as the medium of teaching and learning. The current study makes this original contribution to knowledge. The overarching research question of this study is therefore: To what extent do Language Learning Mindsets of fourth year undergraduate students predict EMI academic success/English language achievement in mechatronics engineering/business administration at a Turkish university?

\section{LITERATURE REVIEW}

\section{Mindset Theory}

Based on the work by Dweck and her colleagues, (Dweck, 1999, 2006; Dweck \& Leggett, 1988; Dweck \& Yeager, 2019; Muller \& Dweck, 1998), the concept of a mindset became an established, influential psychological concept related to motivation adopted in mainstream educational psychology research (Noels et al., 2019). Mindsets are based on two basic assumptions that people hold about their intellectual abilities: (1) some people might think that intellectual abilities are basically fixed and nothing can change their level of intellectual ability (i.e., fixed mindset, entity theory) or (2) some people believe that their intellectual abilities can be improved and developed through hard work and instruction and everyone can develop their underlying ability (i.e., growth mindset, incremental theory; Dweck, 1999). Mindset Theory is the theoretical framework underpinning this study.

\section{Language Learning Mindsets}

Previous studies on language learning mindsets have used both qualitative (Mercer \& Ryan, 2009) and quantitative (Ryan \& Mercer, 2012) analyses on data collected from English as a Foreign Language (EFL) learners in Austria and Japan. These studies explored cross-cultural differences in the conceptualization of mindsets. More recent research has focused on the relationship between language learning mindsets and reading strategies (Molway \& Mutton, 2020), language-based rejection in intercultural communication (Lou \& Noels, 2019), and goal orientation and responses to failure (Lou \& Noels, 2016; 2017). No study has explored the relationship between language learning mindsets, academic achievement, and language achievement. This study fills this research gap.

Language learning mindsets have been applied, adapted, and researched in the field of socio- and applied linguistics (see Lou \& Noels, 2017; Mercer \& Ryan, 2009; Ryan \& Mercer, 2012). However, Lou and Noels argue (2017) that "very little research has specifically addressed fixed versus malleable beliefs about language ability" (p. 215). This study fills this gap by investigating the nuanced differences 
between entity mindsets and incremental mindsets, and their relationship with language achievement. This is done using Lou and Noels' (2017) Language Mindsets Inventory (LMI). The LMI was developed and validated by Lou and Noels in 2017, in what has become one of the most influential studies on LLMs to date. This study therefore explicitly addresses this research gap identified by Lou and Noels (2017).

\section{The Effect of Context on Mindsets}

As briefly mentioned above, it is believed that there are cross-cultural differences in the conceptualization of mindsets. Succinctly, mindsets are thought to be culturally shaped (Dweck \& Leggett, 1988). In their study, Ryan and Mercer (2012) report how students in Austria and Japan have different mindsets that may be rooted in "scripted social discourse" (p. 6) in Japan. Scripted social discourse refers to the participants responses in a questionnaire or interview, which might be grounded in "a schema or scripted discourse about the nature of language learning" ( $p$. 16) popular in that culture rather than participants' actual beliefs about the topic. Lou and Noels (2019) also include contextual influences on language mindsets in their research of mindsets in language learning and teaching. These factors include how experiences impact participants' mindsets in situations such as transition to higher education, study abroad and when students' experience new challenges.

Recently, a meta-analysis conducted by Costa and Faria (2018) revealed different relationships between mindsets and achievement in various settings. For example, studies from Eastern continents such as Asia and Oceania reported a positive link between growth mindset and achievement, but conversely, studies from Europe presented a positive association between entity mindset and achievement. Quite differently, studies from North America found negative correlations between entity mindsets and achievement.

No prior study has examined the LLMs of learners in Turkey, a country located in Eurasia, both geographically and culturally. This study therefore makes an original contribution to knowledge by filling this research gap. It reports the effects of fixed and growth mindsets on academic achievement in the Turkish English Medium Instruction context.

\section{English Medium Instruction}

English Medium Instruction (EMI) is defined here as; "the use of the English language to teach academic subjects other than English itself in countries or jurisdictions where the first language of the majority of the population is not English" (Macaro, 2018, p. 19). The focal context of this study, Turkey, falls within this category. Turkish higher education has witnessed an exponential growth of EMI programs over the last decade (West et al., 2015), however, very little research has explored EMI academic success in Turkey (see Curle et al., 2020b) for an exception.

Previous research on mindsets in the field of language learning has mostly focused on its potential link with language learners' motivation (Lou \& Noels, 2016; Mercer \& Ryan, 2009; 2012). LLM has yet to be explored in an English Medium Instruction context. This study aims to fill this gap.

In the EMI context, English is used as a Medium of Instruction in the teaching of a specific subject. Considering this dual focus on language and content, in our study we examine the predictive power of language mindsets both on language achievement and academic success. Claro et al. (2016), Li et al. (2017) and Pepi et al. (2006) also examined the effects of mindsets on language and academic success in high school and university settings. Pepi et al. (2006) reported significant correlations between language and math achievement and incremental theory in Italian and Portuguese high school and university students. Li et al. (2017) examined the moderating impact of incremental theory of intelligence on prior achievement and school engagement in Chinese high school students. Moreover, in a nationwide study in Chile, Claro et al. (2016) found that incremental theory successfully predicted language and math achievement of high school students. No prior study has examined the effects of language mindsets on language achievement and academic subject success in an EMI context; this study will therefore fill this gap in the research literature.

\section{Mindsets and Academic Success}

Mindset theory claims that mindsets play a critical role in academic success (Rattan et al., 2015). More specifically, entity theory is claimed to be a negative predictor of 
achievement, whereas incremental theory positively predicts academic success (Cury et al., 2006). Some studies reported that mindsets directly predict achievement (Claro et al., 2016; Hong et al., 1999; Muller \& Dweck, 1998; Romero et al., 2014; Zhao \& Wang, 2014). Other studies have found that mindsets directly predict personal characteristics such as goal orientations, beliefs about effort, and strategies for self-regulation, which in turn predict academic success (Blackwell et al., 2007; Dweck \& Leggett, 1998; Müllensiefen et al., 2015; Robins \& Pals, 2002). Some studies have found that mindsets have no predictive power in terms of achievement (Li \& Bates, 2019). A recent meta-analysis on mindsets revealed that mindsets were a weak predictor of academic success (Sisk et al., 2018). In another meta-analysis, Costa and Faria (2018) found that mindsets were "positively related to academic success at a low magnitude" (p. 5) and stated that there might be some discipline-related differences, arguing "incremental theorists are more likely to have higher grades in specific subjects (verbal and quantitative academic domains) and in overall achievement" (Costa \& Faria, 2018, p. 1). This study expands on this strand of research by comparing mechatronics engineering and business administration academic subjects representing physical and social science disciplines.

\section{Discipline-related Differences}

The relationship between mindsets and academic success has been explored in different academic subjects such as math (Blackwell et al., 2007; Bostwick et al., 2017; Tempelaar et al., 2015), biology (Dai \& Cromley, 2014) and statistics and social sciences (Tempelaar et al. 2015), among others. Tempelaar et al. (2015) found that in three different academic subjects, namely math, statistics and social sciences, academic success (i.e., content grades) correlated negatively with incremental theory, and positively with entity theory. On the other hand, Bostwick et al. (2017) found that incremental theory positively predicted engagement and achievement in math, a finding similar to that of Claro et al. (2016).

These contradictory findings, both related to the predictive power of mindsets and achievement according to discipline-based differences, suggest the need for further research into the relationship between academic success and mindsets, particularly in different academic subjects and contexts. Motivated by yet another gap in the literature, this article reports a quantitative study that examines the relationship between LLM, EMI academic success, and English language achievement in two different academic subjects representing two academic divisions; mechatronics engineering (a physical science) and business administration (a social science).

The two broad, overarching research questions of this study are therefore:

1. To what extent do Language Learning Mindsets of fourth year undergraduate students predict EMI academic success/English language achievement in Mechatronics Engineering at a Turkish university?

2. To what extent do Language Learning Mindsets of fourth year undergraduate students predict EMI academic success/English language achievement in Business Administration at a Turkish university?

\section{METHOD}

\section{Setting}

This study was carried out at a public Turkish university with students who were studying a multilingual EMI (Macaro, 2018) program. This is a program in which students were required to take a minimum of two EMI courses per semester in their chosen academic subjects. This university is a major university in Turkey with more than 50,000 students that offers EMI courses in 13 different academic subjects across the science, engineering and economics faculties.

In order to measure the impact of division-based differences we targeted one academic subject in the Mathematics, Life and Physical Sciences (MLPS) division (i.e., mechatronics Engineering) and another from the social sciences division (i.e., business administration). In the mechatronics engineering program, 21 courses were offered in English such as Electric Circuits Theory, Engineering Mathematics, Numerical Methods in Mechatronics Engineering, and Mechatronics Design. There were 42 other courses instructed in Turkish including Elements of Mechatronics, Fluid Mechanics and Electrical Drives. The business administration program offered 20 courses 
instructed in English in the four years of study, including Advanced Readings in Business Administration, Management Information Systems, and Human Resources Management. Forty-two courses were offered in Turkish such as Introduction to Management, Business Mathematics, Management and Organization, and Entrepreneurship and Small Businesses. To summarize, each academic subject included courses taught in EMI as well as the first language (L1) of the students. This gave us an opportunity to examine the effects of LLM on language achievement and academic subject success in the same context.

\section{Participants}

Data for this study were collected from fourth year students studying mechatronics engineering ( $n=68,28 \%$ female) and business administration ( $n=75,52 \%$ female). First, the participants were approached via their EMI course teachers and invited to participate in the study. Then, an email including the link for the online questionnaires was sent out to the official emails of the students and the participants who had volunteered were asked to take part in the study. Out of 87 potential participants in mechatronics engineering, 68 students volunteered to take part in the study. In the business administration group, the emails were sent to 102 students and 75 of them volunteered to participate. All participants were native speakers of Turkish, and studied English as a foreign language in an Intensive English program prior to starting their academic degree programs. The participant age range was between 21 and $26(M=22.6)$ in mechatronics engineering and was between 21 and 29 ( $M$ $=23.2$ ) in business administration.

\section{Instruments and Procedures}

Exam scores of the students on EMI courses as well as English language achievement scores were obtained from the University's registrar office after all the legal and ethical permissions were granted. Data were collected using the following research instruments and measures:

- Students' average scores on business administration and mechatronics engineering content courses taught in English were used as measures for EMI academic success.
- The English language achievement test was an institutional version of the Cambridge Preliminary English Test (PET) at a B1 level of difficulty, which measured students' language skills, namely reading, writing, listening, and speaking.

- Lou and Noels' (2019) LLM Inventory was used to measure language mindsets of the participants (see Appendix).

The LLM questionnaire was translated to Turkish by two native Turkish speakers and an expert, who holds a $\mathrm{PhD}$ in Translation, reviewed the translations and edited them, if necessary. Later, the Turkish version of the questionnaire was back-translated into English and checked by the researchers for any difference. After this, a pilot study was conducted with 20 students of similar characteristics to the main sample. As students did not report any issues related to the items, no changes were made to the questionnaire. The main data collection stage then commenced. Students were contacted via email and requested to take part in the study. The first section of the questionnaire explained all ethical issues to students and requested the consent of the students. Three other sections included items that measured language mindsets of the participants.

In 2017, Lou and Noels (2017) developed and validated the LMI, in what has been one of the most influential studies on LLMs to date. This data instrument consists of nine fixed language mindset items (e.g., It is difficult to change how good you are at learning foreign languages.) and nine growth language mindset items (e.g., People can always substantially change their language intelligence.) set on a 6-point Likert scale from strongly disagree to strongly agree. Cronbach's alpha for internal reliability returned an excellent reliability value with the current data $(r=.93)$ (Dörnyei, 2007). The inventory is based on three themes of language mindsets (i.e., general verbal intelligence, L2 aptitude, and age sensitivity), and includes three fixed language mindset items, and three growth language mindset items for each theme. In this study, we have used the updated version of LMI (Lou \& Noels, 2019), which is provided in the Appendix. 


\section{RESULTS}

Regression analysis results showed that both incremental and entity mindsets predicted academic success in mechanical engineering. Whereas neither mindset was a statistically significant predictor of mechanical engineering students' English language achievement. Business administration students' academic success and English language achievement, however, were both statistically significantly predicted by both incremental and entity mindsets. These differences will be considered in relation to the difference in reliance on language according to each discipline based on theoretical work of Halliday (2004) and Wellington and Osbourne (2001) and previous studies on discipline-related differences in EMI (e.g., Dafouz et al., 2014; Roothooft, 2019). Furthermore, implications of these results both for language professionals and EMI practitioners around the world will also be discussed.
To answer the research questions, simple linear regressions were carried out to investigate the relationship between variables according to academic subject (i.e., mechatronics engineering and business administration).

\section{Language Learning Mindsets in Mechatronics Engineering}

Before modelling the data to answer research question 1 related to mechatronics engineering, the assumptions for simple linear regression were checked. Descriptive statistics are presented in Table 1. On the English language achievement test students scored between $65 \%$ and $96 \%$ $(S D=7.79$; range $=31)$, with a wider range in EMI academic success $(\min =41 \% ; \max =88 \% ; S D=9.28$; range $=47$ ). No variables were significantly skewed or kurtotic, and the data met all the assumptions of regression.

Table 1. Descriptive Statistics of the Mechatronics Engineering sub-dataset

\begin{tabular}{lcccccccccc}
\hline Variable & $n$ & $M$ & $S D$ & median & $\min$ & $\max$ & range & skewness & kurtosis & $S E$ \\
\hline English language achievement & 68 & 76.31 & 7.79 & 75 & 65 & 96 & 31 & 0.45 & -0.90 & 0.94 \\
EMI academic success & 68 & 67.85 & 9.28 & 66 & 41 & 88 & 47 & 0.09 & 0.10 & 1.12 \\
Entity Mindsets & 68 & 3.28 & 3.28 & 1.21 & 1 & 5 & 4 & 0.06 & -1.34 & 0.15 \\
Incremental Mindsets & 68 & 3.22 & 3.22 & 1.17 & 1 & 5 & 4 & -0.32 & -0.91 & 0.14 \\
\hline
\end{tabular}

Neither entity mindsets nor incremental mindsets were statistically significant predictors of English language achievement in mechatronics engineering. However, both mindsets were statistically significant predictors of EMI academic success. Entity mindsets predicted negatively $(t=$ 7.6, $p<.001^{* * * 1}$ ), and explained $45.9 \%$ (adjusted $R^{2}$ ) of the variance in EMI academic success in mechatronics engineering (beta $=-0.68, t=-7.615, p<.001 * * *$ ). The more students felt that their intellectual ability was fixed (entity theory) in Engineering, the lower their grade. While incremental mindsets predicted positively $(t=5.5, p$ $<.001^{* * *}$ ), and explained $30.4 \%$ (adjusted $R^{2}$ ) of the variance in EMI academic success in mechatronics engineering (beta $=0.561, t=5.512, p<.001 * * *$ ). This means that the more students felt that their intellectual ability can be improved and developed through hard work (incremental theory), the higher their grade in engineering.

\section{Language Learning Mindsets in Business Administration}

Again, before modelling the data to answer research question 2, assumptions for simple linear regression were checked on the business administration sub-dataset. Table 2 
shows these descriptive statistics. There was a wide range of scores on EMI academic success $(S D=8.76$; range $=49$ ), with all students scoring more than $60 \%$ on the English language achievement test $(\min =61 \% ; \max =93 \%)$. No variables were significantly skewed or kurtotic, and the data met all assumptions for regression.

Both entity mindsets and incremental mindsets were statistically significant predictors of English language achievement in business administration. Entity mindsets were a negative predictor $(t=5.5, p<.001 * * *)$. The adjusted $R^{2}$ showed that entity mindsets explained $21.9 \%$ of the variance in English language achievement in business administration (beta $=-0.54, t=-5.572, p=.001 * * *$ ). This suggests that the more students felt that their language ability was fixed, the lower their English language grade.

Incremental mindsets were a positive predictor $(t=5.4$, $\left.p<.001^{* * *}\right)$. The adjusted $R^{2}$ showed that incremental mindsets explained $28.3 \%$ of the variance in English language achievement in business administration (beta $=$ $\left.0.54, t=5.54, p<.001^{* * *}\right)$. This shows that the more students felt that their language ability can be improved and developed through hard work (incremental theory), the higher their English language grade.

In relation to EMI academic success in business administration, similar to mechatronics engineering, both entity mindsets and incremental mindsets were statistically significant predictors. Entity mindsets were a negative predictor $(t=8.4, p<.001 * * *)$; the more students felt that their intellectual ability was fixed, the lower their grade. The adjusted $R^{2}$ showed that entity mindsets explained $49 \%$ of the variance in EMI academic success in business administration (beta $=-0.70, t=-8.441, p<.001 * * *$ ). Incremental mindsets were a positive predictor $(t=8.4, p$ $\left.=.001^{* *}\right)$; the more students felt that their intellectual ability can be improved through hard work, the higher their grade. The adjusted $R^{2}$ showed that incremental mindsets explained $48.9 \%$ of the variance in EMI academic success in business administration (beta $=0.704, t=8.43, p$ $<.001 * * *)$.

Table 2. Descriptive Statistics of the Business Administration sub-dataset

\begin{tabular}{lcccccccccc}
\hline Variable & $n$ & $M$ & $S D$ & median & $\min$ & $\max$ & range & skewness & kurtosis & $S E$ \\
\hline English language achievement & 74 & 70.96 & 6.06 & 70 & 61 & 93 & 32 & 1.15 & 1.39 & 0.70 \\
EMI academic success & 74 & 66.69 & 8.76 & 60 & 46 & 95 & 49 & 0.20 & 0.37 & 1.02 \\
Entity Mindsets & 74 & 3.68 & 1.14 & 4 & 1 & 5 & 4 & -0.40 & -0.88 & 0.13 \\
Incremental Mindsets & 74 & 3.03 & 1.18 & 2.5 & 1 & 5 & 4 & 0.59 & -1.27 & 0.14 \\
\hline
\end{tabular}

\section{Discussion}

This study focused on the effects of LLM on academic success in EMI contexts and partially confirmed the findings of previous studies (e.g., Claro et al., 2015; Cury et al., 2006; Pepi et al., 2006). More specifically, our results revealed that incremental LLM positively predicted, and entity LLM negatively predicted EMI academic success in both mechatronics engineering and business administration academic subjects. This is similar to findings from previous studies (Claro et al., 2016; Romero et al., 2014; Zhao \&
Wang, 2014). With a nationwide sample of high school students Chile and colleagues (2016) found that growth mindset was a strong predictor of language and mathematics achievement. Similarly, in Romero et al.'s (2014) study, for example, middle school students with a growth mindset not only earned higher grades but also were more likely to move to advanced math courses over time. Zhao and Wang (2014) used only the statements for entity theory of intelligence and found that junior high students with higher entity scores had lower scores on Chinese, math and English. 
Our results also contradicted those of Tempelaar et al. (2015), who found that entity mindsets positively predicted academic success in three different academic subjects namely math, statistics and the social sciences. Moreover, unlike Costa and Faria's (2016) meta-analytic study, the association between language mindsets and EMI academic success was not low but medium to high. As for the effect of LLM on English language achievement, there were some discipline-based differences between the two academic subjects. Both incremental (positively) and entity (negatively) learning mindsets significantly predicted English language achievement in business administration but not in mechatronics engineering. The association between language mindsets and English language achievement was medium in business administration. These discipline-based differences can be explained by different positioning of language in social sciences and engineering divisions. For example, comparing the perceptions of lecturers in Austria, Italy and Poland, Dearden and Macaro's (2016) study found that lecturers teaching science and math mostly relied on formulae and were less concerned with language issues. However, in the social sciences, teaching and learning involve more interactive, small group seminars, which leads to a heavy reliance on language (i.e., the use of, practice, and need for English, Bolton \& Kuteeva, 2011).

The differences observed in the two academic divisions in our study can be explained by Lou and Noels' (2019) argument that LLMs are domain-specific beliefs and are often related to emotional experiences. They are different from linguistic-related cognitions on topics such as grammar and vocabulary. This notion might explain why there was no association between engineering students' language mindsets and English language achievement. As Shao and colleagues (2019) highlight, there is a wide spectrum of emotions in L2 classrooms, such as enjoyment of learning, relief, happiness, admiration, boredom and shame. These emotions are likely to influence students' motivation and achievement. In content learning for example, Dalton-Puffer (2011) highlights students' worry about not fully understanding academic content due to ambiguity when studying through an L2. This might explain medium to high levels of associations between language mindsets and EMI content achievement in both mechatronics engineering and business administration academic subjects.
Recent research suggests that the relationship between mindset theories and learning might be mediated by other self-theories. According to Dweck (1999) there are various types of self-theories such as mindset theories, effort beliefs, goal setting behavior, intrinsic and extrinsic motivation and self-regulation strategies. In a comprehensive analysis of the associations among self-theories alongside achievement, Tempelaar et al. (2015) found that effort beliefs (effort negative and effort positive) can mediate the relationship between mindset theories and performance. In fact, these scholars used effort beliefs to explain the relationship between mindset theories, performance goals, motivation, and performance. Contrary to expectations, incremental theory was negatively and entity theory was positively correlated with college students' performance. As Lou and Noels (2019) suggest "mindsets are systematically associated with different motivational factors in a complexdynamic meaning-making system" (p. 6). Therefore, it is necessary for future research to investigate the relationship between implicit theories and achievement in combination with other self-theories. Furthermore, individuals' mindsets can be context-dependent and can change over time and across situations (Lou \& Noels, 2019). Thus, further research is needed in order to examine the influences of mindsets in different EMI settings.

\section{Conclusion}

As this study investigated the uncharted territory of language mindsets in an EMI setting, it was not without limitations. The most important limitation was the sample size. The participants were from two academic subjects representing two academic divisions from a public university in Turkey. Larger samples from various academic subjects might yield more generalizable results. Another limitation was that the information of teaching and assessment methods of the courses offered in the two academic divisions in the study are not known. Whether the instructors valued student effort, or whether student competition might have influenced students' mindsets, is unknown. Future university level mindset studies might investigate the possible relationships between teaching strategies, student mindsets, and student learning outcomes.

Lou and Noels (2019) suggest that it is important to inform university students that mindset is an important predictor of achievement and that the idea of a fixed mindset 
might be detrimental to students' prospective success. As Dweck (2014) highlights, recent developments in neuroscience and cognitive psychology have shown that the brain has great plasticity, and some aspects of intelligence can be learned. Helping students understand the brain plasticity and malleability of intelligence will support them in developing a growth mindset. Growth mindsets can be cultivated through intervention. This has been demonstrated through empirical research (see Debacker et al., 2018; Paunesku et al., 2015; Rattan et al., 2015). Underachievers especially benefit from learning about growth mindsets (Paunesku et al., 2015; Sisk et al., 2018; Yeager et al., 2019). Growth mindset interventions deliver students the information that intelligence can grow when they work hard on challenging tasks. They also show that struggle is not a sign of failure but an opportunity for growth (Hwang et al., 2019; Paunesku et al., 2015). Paunesku et al. (2015) claim that since they target a single keystone belief, these interventions can be brief without extensive involvement of researchers or customization of course content. To reach broad samples, online reading and writing assignments regarding the brain's ability to grow through study and practice can benefit students to develop a growth mindset.
As well as students, college professors also need to be informed about the mindset-achievement relationship. Lou and Noels (2019) caution that "helping students to truly endorse growth mindsets is not just about telling them to keep trying" (p. 9). Rather, effective strategies are needed to encourage them to change their mindset (Dweck, 2006; Lou \& Noels). Knowing the fact that the brain makes new connections especially when new and challenging tasks are introduced might positively influence teaching. Instructors might integrate engaging yet challenging materials into their curriculum. Instructors might also need assistance in knowing how to assess student learning more effectively and how to give feedback so that they might promote a growth student mindset. For example, feedback focused on the process emphasizes student effort, whereas outcomefocused feedback focuses on the end product. When students receive outcome-focused feedback, they might start to believe that their ability is fixed, that it cannot change, and therefore may avoid anything challenging, which eventually might lead to poor performance. On the other hand, when feedback is process-focused, students might try harder in order to succeed (Cimpian et al., 2007; Mueller \& Dweck, 1998). These implications all reinforce the importance of mindsets in successful university teaching and learning.

${ }^{1}$ The $*$ indicates the level of significance: $* p \leq .05$,

$* * p \leq .01, * * * p \leq .001$

\section{Author's Contributions}

All authors contributed to the design of the study. DY worked on the data collection and SC worked on data analysis. SK worked on the discussion of the findings. All authors were involved in the writing and editing of the manuscript. All authors read and approved the final manuscript.

\section{Ethics Approval \& Consent to Participate}

Ethics approval was granted by the university where the data was collected (approval no: 2020/13). All participants provided written informed consent prior to enrolment and data collection in the study.

\section{Funding}

The authors received no financial support for this work.

\section{Disclosure Statement}

No conflict of interest was reported by the authors. 


\section{REFERENCES}

Bahník, Š., \& Vranka, M. A. (2017). Growth mindset is not associated with scholastic aptitude in a large sample of university applicants. Personality and Individual Differences, 117, 139-43. https://doi.org/10.1016/j.paid.2017.05.046

Blackwell, L., Trzesniewski, K., \& Dweck, C. S. (2007). Implicit theories of intelligence predict achievement across an adolescent transition: A longitudinal study and an intervention. Child Development, 78, 246-263. https://doi.org/10.1111/j.14678624.2007.00995.x

Bolton, K., \& Kuteeva, M. (2012). English as an academic language at a Swedish university: parallel language use and the 'threat' of English. Journal of Multilingual and Multicultural Development, 33(5), 429-447. https://doi.org/10.1080/01434632.2012.670241

Bostwick, K. C., Collie, R. J., Martin, A. J., \& Durksen, T. L. (2017). Students' growth mindsets, goals, and academic outcomes in mathematics. Zeitschrift für Psychologie, 225, 107-116. https://doi.org/10.1027/2151-2604/a000287

Cimpian, A., Arce, H.M., Markman, E. M., \& Dweck, C. S. (2007). Subtle linguistic cues impact children's motivation. Psychological Science, 18, 314-316. https://doi.org/10.1111/j.1467-9280.2007.01896.x

Claro, S., Paunesku, D., \& Dweck, C. S. (2016). Growth mindset tempers the effects of poverty on academic achievement. Proceedings of the National Academy of Sciences, 113(31), 86648668. https://doi.org/10.1073/pnas.1608207113

Costa, A. \& Faria, L. (2018). Implicit theories of intelligence and academic achievement: A metaanalytic review. Frontiers in Psychology, 9(829), 1-16. https://doi.org/10.3389/fpsyg.2018.00829

Curle, S., Jablonkai, R., Mittelmeier, J., Sahan, K., \& Veitch, A. (2020a). English Medium Part 1: Literature review. In N. Galloway (Ed.), English in higher education (Report No. 978-0-86355977-8). British Council. https://www.teachingenglish.org.uk/article/english -higher-education-\%E2\%80\%93-english-mediumpart-1-literature-review

Curle, S., Yuksel, D., Soruç, A., Altay, M. (2020b).

Predictors of English medium instruction academic success: English proficiency versus first language medium. System, 95. https://doi.org/10.1016/j.system.2020.102378

Cury, F., Elliot, A. J., Da Fonseca, D., \& Moller, A. C. (2006). The social-cognitive model of achievement motivation and the $2 \times 2$ achievement goal framework. Journal of Personality and Social Psychology, 90(4), 666-679. https://doi.org/10.1037/0022-3514.90.4.666

Dafouz, E., Camacho, M., \& Urquia, E. (2014). "Surely they can't do as well": A comparison of business students' academic performance in Englishmedium and Spanish-as-a-first-language medium programs. Language and Education, 28(3), 223236.

https://doi.org/10.1080/09500782.2013.808661

Dalton-Puffer, C. (2011). Content-and-language integrated learning: From practice to principles? Annual Review of Applied Linguistics, 31, 182-204. https://doi.org/10.1017/S0267190511000092

Dearden, J., \& Macaro, E. (2016). Higher education teachers' attitudes towards English medium instruction: A three-country comparison. Studies in Second Language Learning and Teaching, 6(3), 455-486. https://doi.org/10.14746/sllt.2016.6.3.5

DeBacker, T. K., Heddy, B. C., Kershen, J. L., Crowson, H. M., Looney, K., \& Goldman, J. A. (2018). Effects of a one-shot growth mindset intervention on beliefs about intelligence and achievement goals. Educational Psychology, 38(6), 711-733. https://doi.org/10.1080/01443410.2018.1426833

Dörnyei, Z. (2007). Research methods in applied linguistics: Quantitative, qualitative, and mixed methodologies. Oxford University Press. 
Dweck, C. S. (1999). Self-theories: Their role in motivation, personality and development. Psychology Press.

Dweck, C. S. (2006). Mindset. Random House.

Dweck, C. S. (2014). Mindsets and math/science achievement. Carnegie Corporation.

Dweck, C. S., \& Leggett, E. L. (1988). A social-cognitive approach to motivation and personality. Psychological review, 95(2), 256-273. https://doi.org/10.1037/0033-295X.95.2.256

Dweck, C. S., \& Yeager, D. S. (2019). Mindsets: A view from two eras. Perspectives on Psychological Science, 14(3), 481-496.

https://doi.org/10.1177/1745691618804166

Halliday, M. A. K. (2004). The language of science: The collected works of M.A.K. Halliday. Volume 5. Continuum.

Hong, Y. Y., Chiu, C. Y., Dweck, C. S., Lin, D. M. S., \& Wan, W. (1999). Implicit theories, attributions, and coping: A meaning system approach. Journal of Personality and Social Psychology, 77(3), 588599. https://doi.org/10.1037/0022-3514.77.3.588

Li, P., Zhou, N., Zhang, Y., Xiong, Q., Nie, R., \& Fang, X. (2017). Incremental theory of intelligence moderated the relationship between prior achievement and school engagement in Chinese high school students. Frontiers in Psychology, 8(1703). https://doi.org/10.3389/fpsyg.2017.01703

Li Y., \& Bates, T.C. (2019). You can't change your basic ability, but you work at things, and that's how we get hard things done: Testing the role of growth mindset on response to setbacks, educational attainment, and cognitive ability. Journal of Experimental Psychology: General, 148(9), 1640 1655. https://doi.org/10.1037/xge0000669

Lou, N. M., \& Noels, K. A. (2016). Changing language mindsets: Implications for goal orientations and responses to failure in and outside the second language classroom. Contemporary Educational Psychology, 46, 22-33.

https://doi.org/10.1016/j.cedpsych.2016.03.004
Lou, N. M., \& Noel, K. A. (2017). Measuring language mindsets and modeling their relations with goal orientations and emotional and behavioural responses in failure situations. The Modern Language Journal, 101, 22-33. https://doi.org/10.1111/modl.12380

Lou, N. M., \& Noels, K. A. (2019). Promoting growth in foreign and second language education: A research agenda for mindsets in language learning and teaching. System, 86, 102-126. https://doi.org/10.1016/j.system.2019.102126

Macaro, E. (2018). English medium instruction. Oxford University Press.

Macaro, E., Curle, S., Pun, J., An, J., \& Dearden, J. (2018). A systematic review of English medium instruction in higher education. Language Teaching, 51(1). https://doi.org/10.1017/S0261444817000350

Mercer, S., \& Ryan, S. (2009). A mindset for EFL: Learners' beliefs about the role of natural talent. ELT Journal, 64(4), 436-444. https://doi.org/10.1093/elt/ccp083

Molway, L., \& Mutton, T. (2020). Changing mindsets in the modern foreign languages classroom: An intervention combining intelligence theories and reading strategies. The Language Learning Journal, 48(5), 598-612. https://doi.org/10.1080/09571736.2018.1554693

Muller, C., \& Dweck, C. S. (1998). Praise for intelligence can undermine children's motivation and performance. Journal of Personality and Social Psychology, 75(1), 33-52. https://doi.org/10.1037/0022-3514.75.1.33

Müllensiefen, D., Harrison, P., Caprini, F., \& Fancourt, A. (2015). Investigating the importance of selftheories of intelligence and musicality for students' academic and musical achievement. Frontiers in Psychology, 6(1702). https://doi.org/10.3389/fpsyg.2015.01702

Noels, K. A., Lou, N. M., Vargas Lascano, D. I., Chaffee, K. E., Dincer, A., Zhang, Y. S. D., \& Zhang, X. J. (2019). Self-determination and motivated engagement in language learning. In M. Lamb, K. 
Csizér, A, Henry, \& S. Ryan (Eds.), The Palgrave handbook of motivation for language learning (pp. 95-115). Palgrave MacMillan.

Paunesku, D., Walton, G. M., Romero, C., Smith, E. N., Yeager, D. S., \& Dweck, C. S. (2015). Mind-set interventions are a scalable treatment for academic underachievement. Psychological Science, 26(6), 784-793.

https://doi.org/10.1177/0956797615571017

Pepi, A., Faria, L., \& Alesi, M. (2006). Personal conceptions of intelligence, self-esteem, and school achievement in Italian and Portuguese students. Adolescence, 41, 615-631.

Rattan, A., Savani, K., Chugh, D., \& Dweck, C. S. (2015). Leveraging mindsets to promote academic achievement: Policy recommendations. Perspectives on Psychological Science, 10, 721726. https://doi.org/10.1177/1745691615599383

Romero, C., Master, A., Paunesku, D., Dweck, C. S., \& Gross, J. J. (2014). Academic and emotional functioning in middle school: The role of implicit theories. Emotion, 14(2), 227-234. https://doi.org/10.1037/a0035490

Roothooft, H. (2019). Spanish lecturers' beliefs about English medium instruction: STEM versus humanities. International Journal of Bilingual Education and Bilingualism. https://doi.org/10.1080/13670050.2019.1707768

Ryan, S., \& Mercer, S. (2012). Language learning mindsets across cultural settings: English learners in Austria and Japan. OnCUE Journal, 6(1), 6-22.

Shao, K., Pekrun, R., \& Nicholson, L. J. (2019). Emotions in classroom language learning: What can we learn from achievement emotion research?
System, 86, 102-121.

https://doi.org/10.1016/j.system.2019.102121

Sisk, V. F., Burgoyne, A. P., Sun, J., Butler, J. L., \& Macnamara, B. N. (2018). To what extent and under which circumstances are growth mind-sets important to academic achievement? Two metaanalyses. Psychological Science, 29(4), 549-571. https://doi.org/10.1177/0956797617739704

Tempelaar, D. T., Rienties, B., Giesbers, B., \& Gijselaers, W. H. (2015). The pivotal role of effort beliefs in mediating implicit theories of intelligence and achievement goals and academic motivations. Social Psychology of Education, 18(1), 101-120. https://doi.org/10.1007/s11218-014-9281-7

Wellington, J., \& Osborne, J. (2001). Language and literacy in science education. Open University Press.

West, R., Güven, A., Parry, J., \& Ergenekon, T. (2015). The state of English in higher education in Turkey. British Council and TEPAV. Retrieved from https://www.britishcouncil.org.tr/sites/default/files /he_baseline_study_book_web_-_son.pdf

Yeager, D. S., Hanselman, P., Walton, G. M., Murray, J. S., Crosnoe, R., Muller, C. ... \& Paunesku, D. (2019). A national experiment reveals where a growth mindset improves achievement. Nature, 573(7774), 364-369. https://doi.org/10.1038/s41586-019-1466-y

Zhao, J., \& Wang, M. (2014). Mothers' academic involvement and children's achievement: Children's theory of intelligence as a mediator. Learning and Individual Differences, 35, 130-136. https://doi.org/10.1016/j.lindif.2014.06.006

\section{APPENDIX}

General language intelligence beliefs (GLB):

1. You have a certain amount of language intelligence, and you can't really do much to change it.

2. Your language intelligence is something about you that you can't change very much.

3. To be honest, you can't really change your language intelligence.

*4. No matter who you are, you can significantly change your language intelligence level.

${ }^{*} 5$. You can always substantially change your language intelligence.

${ }^{*} 6$. No matter how much language intelligence you have, you can always change it quite a bit. 
Second language aptitude beliefs (L2B):

1. To a large extent, a person's biological factors (e.g., brain structures) determine his or her abilities to learn new languages.

2. It is difficult to change how good you are at foreign languages.

3. Many people will never do well in foreign languages even if they try hard because they lack natural language intelligence.

*4. You can always change your foreign language ability.

*5. In learning a foreign language, if you work hard at it, you will always get better.

${ }^{*} 6$. How good you are at using a foreign language will always improve if you really work at it.

Age sensitivity beliefs about language learning (ASB):

1. How well a person speaks a foreign language depends on how early in life he/she learned it.

2. People can't really learn a new language well after they reach adulthood.

3. Even if you try, the skill level you achieve in a foreign language will advance very little if you learn it when you are an adult.

*4. Everyone could do well in foreign language if they try hard, whether they are young or old.

*5. How well a person learns a foreign language does not depend on age; anyone who works hard can be a fluent speaker in that language

${ }^{*} 6$. Regardless of the age at which they start, people can learn another language well.

Note. ${ }^{*}$ These items are incremental theory (i.e., growth mindset) items. 